\title{
Job Satisfaction among the Faculty Members of Nursing Colleges in Saudi Arabia
}

\author{
Mysara Alfaki ${ }^{1}$, Ahmed S. Alkarani ${ }^{2}$ \\ 1, 2 Department of Nursing, Taif University, Taif, Saudi Arabia.
}

\section{ABSTRACT}

\section{BACKGROUND}

Job satisfaction has a significant impact on the work behaviour of faculty members and their attitudes to their work. However, to the best of our knowledge, there are no recent studies on job satisfaction among the faculty members of nursing colleges in Saudi Arabia. The purpose of the current study was to explore the factors influencing job satisfaction among nursing department faculty members of nursing colleges in Saudi universities.

\section{METHODS}

This online survey was approved by Taif University under code (42 - 0085). A 35 item ( 6 dimensions) five option Likert - type draft questionnaire on job satisfaction was distributed for online anonymous self-reporting by the faculty members of nursing colleges in Saudi universities $(\mathrm{N}=116)$.

\section{RESULTS}

The general level of overall job satisfaction (OJS) of the faculty members of nursing colleges in Saudi universities on all dimensions of job satisfaction is observed to be low (0JS mean 1,28), while work itself and interpersonal relationships were high. The dimensions of job satisfaction were analysed by path coefficient and the significance test. First, for faculty member's job satisfaction as a higher order factor consists of 6 first order factors: the influence of salary and welfare on job satisfaction is the greatest, with a path coefficient reaching .580. Next comes job competence, leader behaviour, interpersonal relationships, and the work itself.

\section{CONCLUSIONS}

A seven-factor job satisfaction model is advanced, including one high order factor (job satisfaction) and six first-order factors (salary and welfare, the work itself, leader behaviour, personal growth, interpersonal relationships and job competence) demonstrated good overall psychometric properties in terms of construct validity and internal consistency reliability in both the overall sample and its separately analysed subgroups.

\section{KEY WORDS}

Faculty Members, Job Satisfaction, Nursing Colleges, Quality of Higher Education, Saudi Arabia

\author{
Corresponding Author: \\ Dr. Ahmed S. Alkarani, \\ Assistant Professor in the \\ Nursing department at \\ Faculty of Applied Medical \\ Sciences, Taif University, \\ Saudi Arabia. \\ E-mail:asakg@live.com.
}

DOI: $10.14260 / \mathrm{jemds} / 2021 / 629$

How to Cite This Article:

Alfaki M, Alkarani AS. Job satisfaction among the faculty members of nursing colleges in Saudi Arabia. J Evolution Med Dent Sci 2021;10(36):3083-3087, DOI: 10.14260/jemds/2021/629

Submission 07-05-2021,

Peer Review 26-07-2021,

Acceptance 03-08-2021,

Published 06-09-2021.

Copyright (C) 2021 Mysara Alfaki et al. This is an open access article distributed under Creative Commons Attribution License [Attribution 4.0 International (CC BY 4.0)] 


\section{BACKGROUND}

Job satisfaction has a significant impact on the work behaviour of faculty members and their attitudes to their work. There is an increasing interest in determining the level of job satisfaction in higher education and its impact on the performance of academics. However, to the best of our knowledge, there are no recent studies on job satisfaction among the faculty members of nursing colleges in Saudi Arabia. Job satisfaction has been considered as a major issue in educational institutions since it is closely related to the job performance and turnover of employees. ${ }^{1}$ In addition, a group of researchers analysed the factors affecting job satisfaction and their correlation with educational standards among dental assistants working in various dental schools, clinics, polyclinics, private and public hospitals in 297 factors predicting job satisfaction in Saudi Arabia. ${ }^{2}$ Furthermore, Al Smadi and Qblan ${ }^{3}$ evaluated the level of job satisfaction among faculty members at Najran University and identified the impact of variables such as gender, teaching experience and college on their job satisfaction. A recent study ${ }^{4}$ described the predictors of the level of job satisfaction among female faculty members of the health sciences in Saudi Arabia using the Minnesota satisfaction questionnaire (MSQ). The study also explored the relationship between the faculty's level of job satisfaction and their demographic characteristics. El - Zoubi and Wirba ${ }^{5}$ examined the job satisfaction of the academic staff in various academic institutions of the Eastern province of Saudi Arabia using a job satisfaction questionnaire developed by Spector.

Currently in Saudi Arabia, the National Center for Academic Accreditation and Assessment (NCAAA) is responsible for granting and monitoring the academic accreditation processes of HEIs. It is mandatory for HEIs to assess their performance by conducting various evaluations by students and faculty members in order to meet its requirements for academic accreditation. This study defined the factors influencing the job satisfaction of nursing college faculty members as salary and welfare, leader behavior, the work itself, interpersonal relationships, job competence and personal growth, and this study posits the following hypotheses - H1a: Salary and welfare are positively related to job satisfaction among the faculty members of nursing colleges; H1b: Leader behavior is positively related to job satisfaction among the faculty members of nursing colleges; H1c: Work itself is positively related to job satisfaction among the faculty members of nursing colleges; H1d: Interpersonal relationships are positively related to job satisfaction among the faculty members of nursing colleges; H1e: Job competence is positively related to job satisfaction among the faculty members of nursing colleges; H1f: Personal growth is positively related to job satisfaction among the faculty members of nursing colleges.

\section{Objectives}

The overall purpose of the current study was to explore the factors influencing job satisfaction among nursing department faculty members of nursing colleges in Saudi universities. This study has many objectives:
- To observe the general level of overall job satisfaction (OJS) of the faculty members of nursing colleges in Saudi universities on all dimensions of job satisfaction.

- To compare the overall job satisfaction of faculty members of the nursing colleges with respect to gender.

- To compare the overall job satisfaction of faculty members of the nursing colleges with respect to nationality,

- To observe which of the six first-order factors (salary and welfare, the work itself, leader behaviour, personal growth, interpersonal relationships and job competence) are positively related to job satisfaction among the faculty members of nursing colleges.

\section{METHODS}

In this study, an exploratory design was adopted and the faculty members of the nursing colleges in Saudi universities were considered as its population. The term "faculty" included professors, associate professors, assistant professors, lecturers, a teaching assistant and a clinical instructor and others directly involved in teaching. To capture the level of job satisfaction of faculty members, this study used a Minnesota six factors model content - validated questionnaire entitled the Minnesota JSQ questionnaire, which is a modified version of the instrument developed by Xianyin Lee et al. ${ }^{6}$

The questionnaire was administered online to faculty members $(\mathrm{N}=116)$ who agreed to participate in this study using an online application "google form". The questionnaire consisted of 6 dimensions with a total of 34 items and one global rating item (overall job satisfaction). The dimensions used in JS were salary and welfare, the work itself, leader behaviour, personal growth, interpersonal relationships, and job competence. In this study, these dimensions were designated as factors influencing job satisfaction among faculty members at nursing colleges. Each item has a Likert type scale, and the response was rated using a five point ordinal scale, designated as Strongly Agree (5), Agree (4), Neutral (3), Disagree (2), and Strongly Disagree (1). To avoid common method variance, some reverse problems were provided in the scale. After data collection, the corresponding data were treated with reverse processing.

The study used online survey and a 35-item, five-option Likerttype draft questionnaire was used for the purpose.

The current study was conducted between $30^{\text {th }}$ of October 2020 and $5^{\text {th }}$ of February 2021.

\section{Ethical Statement}

The ethical considerations were adhered to, informed consent was obtained, and confidentiality and anonymity were assured before collecting the data from the participants. A stipulated timeframe was provided to them to respond. 116 completed responses were received. Moreover, this online survey was approved by Taif University under code (42 - 0085).

\section{Statistical Analysis}

Statistical analysis was done using SPSS version 16. The evaluation of the internal consistency of the questionnaire was done using the Cronbach $\alpha$ reliability test. Descriptive 
statistics were used for demographic data and the level of job satisfaction among faculty members. An independent $t$ - test was used to compare the overall job satisfaction of faculty members with respect to gender and nationality. Pearson's correlation was applied to determine the relationship between the overall job satisfaction and dimensions of JS. Furthermore, the influence of 6 dimensions of JS (independent variables) on the overall job satisfaction of faculty members (dependent variable) was assessed using multiple regression analysis.

\section{RESULTS}

The characteristics of faculty members are shown in Table 1. In terms of gender, (61.2\%) were females and (38.8\%) males. More than half of the participants (58.6\%) were non-Saudi. This study revealed that most participants belonged to the age group of $31-40$ years (41.4\%). Most of the participants had a $\mathrm{PhD}$ degree (62.1\%) and their current positions were assistant professors (47.4\%) and their monthly household income was between 10000 - 20000 Saudi riyals (SAR)(82.8 $\%)$. Furthermore, an independent sample " $t$ " test was applied to compare the overall job satisfaction of faculty members of the nursing colleges with respect to gender and nationality.
In case of gender, the results showed that there was no significant difference in overall job satisfaction between male and female faculty members $P$ value 0.50 . Similarly, no significant difference was observed in overall job satisfaction between Saudi and non-Saudi faculty members P value 0.16 Table 1 . The attitudes of faculty members were shown in Table 2 and the participants responses on the questions toward JS dimensions.

Most respondents reported "Strongly Agree" on dimensions such as work itself (WI), Interpersonal relationships (IR), and overall job satisfaction (OJS) 60.3, 61.2, 58.6 respectively, and some respondents reported "Strongly Disagree" toward Salary and welfare (SW), leader behavior (LB) and Personal growth (PG) $6.0 \%, 9.5 \%$ and $12.9 \%$ respectively. In addition, the internal consistency of the instrument used for data collection was tested by using the Cronbach's $\alpha$ reliability test, the overall Cronbach's alpha reliability coefficient of the job satisfaction scale was 0.85. Cronbach's alpha for the 6 dimensions of job satisfaction, namely salary and welfare, leader behaviour, personal growth, work itself, interpersonal relationships, and job competency, were $0.77,0.61,0.71,0.82,0.51$ and 0.70 respectively. (Table 2)

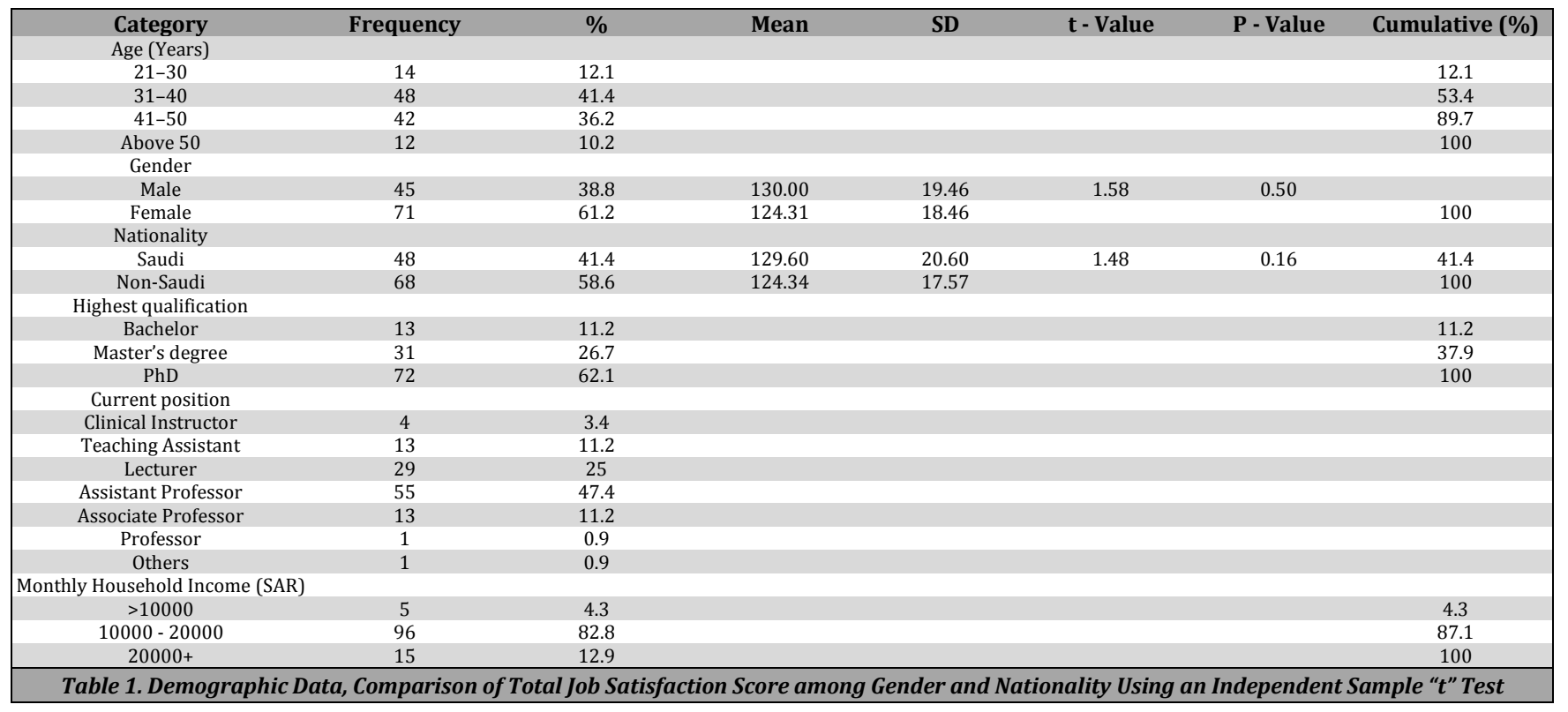

\begin{tabular}{|c|c|c|c|c|c|c|c|}
\hline Dimensions & $\begin{array}{c}\text { Strongly Agree } \\
(\%)\end{array}$ & Agree (\%) & Neutral (\%) & Disagree (\%) & $\begin{array}{l}\text { Strongly } \\
\text { Disagree }\end{array}$ & Cronbach's $\alpha$ Alpha & No. of Items \\
\hline Salary and welfare & 42.2 & 31.0 & 14.7 & 6.0 & 6.0 & 0.77 & 06 \\
\hline Leader behaviour & 46.6 & 29.3 & 11.2 & 3.4 & 9.5 & 0.61 & 06 \\
\hline Personal growth & 29.3 & 29.3 & 17.2 & 11.2 & 12.9 & 0.71 & 05 \\
\hline Work itself & 60.3 & 31.0 & 4.3 & 3.4 & 0.9 & 0.82 & 06 \\
\hline Interpersonal relationships & 61.2 & 25.0 & 11.2 & 2.6 & 0.0 & 0.51 & 06 \\
\hline Job competency & 40.5 & 26.7 & 9.5 & 18.1 & 5.2 & 0.70 & 05 \\
\hline Overall job satisfaction & 58.6 & 27.6 & 3.4 & 6.9 & 3.4 & 0.85 & 34 \\
\hline \multicolumn{8}{|c|}{ Table 2. Percentage of Respondents toward JS Variables \& Reliability Statistics } \\
\hline
\end{tabular}

\begin{tabular}{|c|c|c|c|c|c|c|c|c|c|c|c|}
\hline Path Coefficients & Mean & SD & SW & WI & LB & PG & IR & JC & OJS & SL & P Value \\
\hline SW $<--0 J S$ & 21.68 & 4.64 & 1 & & & & & & & 0.580 & $0.00^{* *}$ \\
\hline WI $<--$ OJS & 24.93 & 3.74 & $0.48^{* *}$ & 1 & & & & & & 0.311 & $0.03^{*}$ \\
\hline$L B<--0 J S$ & 22.37 & 5.44 & $0.61^{* *}$ & $0.48^{* *}$ & 1 & & & & & 0.531 & $0.011^{*}$ \\
\hline$P G<--O J S$ & 19.77 & 3.86 & $0.69 * *$ & $0.52^{* *}$ & $0.60^{* *}$ & 1 & & & & 0.298 & $0.020^{*}$ \\
\hline$I R<--0 J S$ & 23.80 & 4.66 & $0.42 * *$ & $0.67^{* *}$ & $0.44^{* *}$ & $0.3^{* *}$ & 1 & & & 0.453 & 0.955 \\
\hline $\mathrm{JC}<--$ OJS & 16.42 & 2,85 & $0.14^{* *}$ & $0.35^{* *}$ & $0.42^{* *}$ & $0.19^{* *}$ & $0.48^{* *}$ & 1 & & 0.537 & $0.001^{* *}$ \\
\hline OJS & 1,28 & 18.90 & $0.78^{* *}$ & $0.78^{* *}$ & $0.83^{* *}$ & $0.76^{* *}$ & $0.75^{* *}$ & $0.53^{* *}$ & 1 & - & - \\
\hline
\end{tabular}

Table 3. Descriptive Statistical Results of Variables and the Correlation Matrix and Path Coefficients of Each Dimension and the Significance Test Notes: SW, Salary and welfare, LB, leader behavior, PG, Personal growth, WI, Work itself, IR, Interpersonal relationships, JC, Job competency, OJS, overall job satisfaction, SL, Standard load. *indicates $P<.5, * *$ indicates $P<.01$ 
SPSS 16.0 was employed to derive the descriptive statistical analysis of the variables and the correlation matrix between the variables, as shown in Table 3. Through descriptive statistical analysis and the correlation matrix, the correlation coefficients between an employee's job satisfaction and its six dimensions were judged to be in the range of .83 and .34 , and they passed the significance test $(\mathrm{P}<$ $.01)$.

In Table 3, the standard loads of six dimensions - namely salary and welfare, the work itself, leader behaviour, personal growth, interpersonal relationships, and job competence - on job satisfaction were $0.580,0.311,0.531,0.298,0.453$ and 0.537 , respectively. The influence of the six dimensions on the higher order factor, namely job satisfaction was significant below the .05 level, and the order of the influence was personal growth, salary and welfare, job competence, leader behaviour, personal growth, and the work itself.

The six hypotheses proposed in this research, namely H1a, H1b, H1c, H1e and H1f, were empirically supported, except for the factor of interpersonal relationships.

\section{DISCUSSION}

This study included academic nursing faculty members in Saudi Arabian universities as research subjects, and 116 valid questionnaires were collected using the convenience sampling method. The six factors analysis method model was employed to perform an empirical study of the factors influencing employees' job satisfaction. The paper involved one variable, namely job satisfaction. The results of the exploratory factor analysis showed that job satisfaction had good structure validity, which could reflect the real situation of the job satisfaction of nursing faculty members. The job satisfaction proposed in this study was based on the Minnesota Satisfaction Questionnaire. Combined with domestic studies on job satisfaction, this research performed a more complete and precise study of the constituent dimensions of job satisfaction from a micro perspective. A seven-factor job satisfaction model was advanced, including one high order factor (job satisfaction) and six first-order factors (salary and welfare, the work itself, leader behaviour, personal growth, interpersonal relationships, and job competence).

In this study, the overall Cronbach's alpha reliability coefficient of the job satisfaction scale was 0.85. Cronbach's alpha for the 6 dimensions of job satisfaction - namely salary and welfare, leader behaviour, personal growth, the work itself, interpersonal relationships, and job competence - which is similar to the findings of Xianyin Lee et al. ${ }^{6}$ But it is markedly low when compared to the results observed by $\mathrm{Al}$ Kuwaiti et al. ${ }^{7}$ among faculty members of the health sciences programmed at a Saudi higher education institution. The overall $\alpha$ coefficient value 0.96 showed that the variables measuring the concept of the questionnaire can be rated as "excellent".

Regarding the percentages of respondents' ratings on the dimensions of JS, it was found that about $61.0 \%$ of faculty members were satisfied (reported strongly agree) with leader behaviour, which was lower than the findings reported by Mahdi et al. ${ }^{8}$ but considerably high when compared to the results observed by El - Zoubi and Wirba ${ }^{9}$ among academic staff in Saudi universities. On the contrary, few studies indicate that supervisory style is not a strong predictor of employee's job satisfaction. ${ }^{10}$ About $73.2 \%$ of faculty members showed a positive response to salary [i.e. strongly agree $(42.2 \%)$ and agree (31.0\%)], which was higher than the results of a previous study that demonstrated 61 percent of respondents were satisfied with the pay, salary and benefits packages. A study by Al - Smadi and Qblan reported a moderate degree of overall job satisfaction among faculty members at Najran University in Saudi Arabia. In contrast, our study reported a high level of overall job satisfaction among faculty members of the nursing colleges. With respect to the dimensions of JS, these nursing colleges' faculty members reported a high level of satisfaction with all the dimensions of JS except for personal growth.

The present study showed no significant difference in overall job satisfaction among nursing college faculty members at Saudi universities with respect to nationality, i.e., the Saudi faculty members were just as satisfied as the non Saudi faculty members. Some $41.4 \%$ of the samples of this present study were Saudi nationals. Our finding is in contrast with the results of Praveen ${ }^{11}$ that showed nationality had a significant effect on job satisfaction, wherein the Saudi faculty members were more satisfied with personal growth, salary and professional support than their non-Saudi counterparts. Further, subsequently, our study revealed that salary was the most important predictor of overall job satisfaction among health sciences' faculty members, which was validated by earlier studies of Masum et al. (2015); From Herzberg's point of view, salary is considered as a job dissatisfaction element. ${ }^{12}$

Furthermore, all dimensions of JS are positively correlated with overall job satisfaction, which is consistent with the findings of other studies which reported a positive correlation between job motivation factors such as achievement, advancement, recognition, responsibility, the work itself and overall job satisfaction among faculty members. Also, it was observed that job hygiene factors such as relationships, policy and administration, salary, supervision, and work conditions were positively related to overall job satisfaction. As IAU is a public HEI, a positive relationship was found between JS and overall job satisfaction among the faculty members of health sciences, and this was in line with the findings of many studies which indicated that employees in the public sector were more satisfied with their jobs compared to the private sector. ${ }^{13}$

Moreover, this study revealed that all the dimensions of JS except interpersonal relationships were significant predictors of overall job satisfaction among the faculty members of nursing colleges at Saudi universities. Leader behaviour was observed as one of the significant factors influencing job satisfaction among faculty members, which is consistent with the findings of many studies. ${ }^{14}$ Previous studies also demonstrated that those supervisors maintain a strong IR with their colleagues' results in the enhancement of employees' job satisfaction at the workplace. ${ }^{15}$ On the other hand, a few studies indicate that supervisory style is not a strong predictor of employees' job satisfaction. ${ }^{16}$

Finally, standard loads of six dimensions in this study observed the personal growth, salary and welfare, job competence, leader behaviour, personal growth, and the work itself as significant predictors of job satisfaction among nursing college faculty members at Saudi universities. These findings are in accordance with the results of Britiller and 
Thabet, who found that the intrinsic factors focusing on the meaningful use of time at work, collegial relationship, work values, work independence and chances and opportunities for professional growth were predictors of the level of job satisfaction among faculty members of the $\mathrm{Al}$ Ghad international colleges of health sciences in Saudi Arabia.

In addition, this study revealed that job promotion had a significant influence on job satisfaction among academic staff, whereas job responsibilities had no significant effect on job satisfaction. ${ }^{17}$

\section{CONCLUSIONS}

The current study increases the value of the current literature by investigating the factors influencing the job satisfaction of nursing college faculty members in Saudi universities. The article concludes that most respondents strongly agreed on dimensions such as the work itself (WI), interpersonal relationships (IR) and overall job satisfaction, while some respondents strongly disagreed when it came to salary and welfare (SW), leader behaviour (LB) and personal growth (PG). Moreover, this study reveals that all the 6 dimensions of JS, except for interpersonal relationships, are significant predictors of overall job satisfaction among the faculty members of nursing colleges at Saudi universities.

Stakeholders should gadget proper strategies to actualize the uniform rules and regulations laid down by the Ministry of Education regarding pay, advantages, residency and occupation progression; workload standardization; upgrade of the PR of faculty members; guaranteeing a decent workplace; provision of rewards and acknowledgment with suitable professional success; making attention to authoritative strategies among faculty members and advancing administrative help and IR among collaborators. By these means, universities can remedy every factor influencing job satisfaction among their employees and improve their productivity.

Data sharing statement provided by the authors is available with the full text of this article at jemds.com.

Financial or other competing interests: None.

Disclosure forms provided by the authors are available with the full text of this article at jemds.com.

\section{REFERENCES}

[1] Agnihotri A. Job satisfaction among school teachers. Indian Streams Research Journal 2013;3(2):1-7.

[2] Al Jazairy YH, Halawany HS, Al Hussainan N, et al. Factors affecting job satisfaction and their correlation with educational standards among dental assistants. Ind Health 2014;52(4):324-33.

[3] Al-Smadi MS, Qblan YM. Assessment of job satisfaction among faculty members and its relationship with some variables in Najran University. Journal of Education and Practice 2015;6(35):117-23.
[4] Britiller MC, Thabet RA. Predictors of job satisfaction of faculty members of Al Ghad International College for health sciences. Asia Pacific Journal of Multidisciplinary Research 2015;3(2):63-8.

[5] El-Zoubi JR, Wirba AV. Academic staff job satisfaction in Saudi Arabia: a case study of academic institutions in the Eastern Province of Saudi Arabia. Research on Humanities and Social Sciences 2017;7(2):73-89.

[6] Lee X, Yang B, Li W. The influence factors of job satisfaction and its relationship with turnover intention: taking earlycareer employees as an example. Anales De Psicología 2017;33(3):697-707.

[7] Al Kuwaiti A, Bicak HA, Wahass S. Factors predicting job satisfaction among faculty members of a Saudi higher education institution. Journal of Applied Research in Higher Education 2019;12(2):296-310.

[8] Mahdi SA, Almarshad So, Elsiddig BMA, et al. Northern border university academic staff job satisfaction. International Journal of Information Technology and Business Management 2014;25(1):121-32.

[9] El-Zoubi JR, Wirba AV. Academic staff job satisfaction in Saudi Arabia: a case study of academic institutions in the Eastern Province of Saudi Arabia. Research on Humanities and Social Sciences 2017;7(2):73-89.

[10] Al - Smadi MS, Qblan YM. Assessment of job satisfaction among faculty members and its relationship with some variables in Najran University. Journal of Education and Practice. 2015;6(35):117 - 123.

[11] Praveen M. Healthcare industry in Saudi Arabia: demographic effect on job satisfaction and retention. International Journal of Business and Social Science 2015;6(9):78-88.

[12] Masum AKM, Azad MAK, Beh LS. Determinants of academics job satisfaction: empirical evidence from private universities in Bangladesh. PLoS One 2015;10(2):e0117834

[13] Alam MGR, Masum AKM, Beh LS, et al. Critical factors influencing decision to adopt human resource information system (HRIS) in hospitals. PLoS One 2016;11(8):e0160366.

[14] Khalid S, Irshad M, Mahmood B. Job satisfaction among academic staff: a comparative analysis between public and private sector Universities of Punjab, Pakistan. International Journal of Business and Management 2012;7(1):126-36.

[15] Malik ME, Nawab S, Naeem B, et al. Job satisfaction and organizational commitment of university teachers in public sector in Pakistan. International Journal of Business Management 2010;5(6):17-26.

[16] Alpern R, Canavan ME, Thompson JT, et al. Development of a brief instrument for assessing healthcare employee satisfaction in a low-income setting. PLoS One 2013;8(11):e79053.

[17] Jawabri A. Job satisfaction of academic staff in the higher education: evidence from private universities in UAE. International Journal of Human Resource Studies 2017;7(4):193-211. 